\title{
The Use of Interactive Whiteboards to Support the Creation, Capture and Sharing of Knowledge in South African Schools
}

\author{
Hannah Slay ${ }^{1}$, Ingrid Siebörger ${ }^{1}$ and Cheryl Hodgkinson-Williams ${ }^{2}$ \\ ${ }^{1}$ Computer Science Department, Rhodes University \\ Grahamstown. South Africa, 6139 [h.slay,i.sieborger]@ru.ac.za \\ WWW home page: http://www.cs.ru.ac.za \\ ${ }^{2}$ Education Department, Rhodes University \\ Grahamstown. South Africa, 6139 chodgkinsonwilliams@gmail.com
}

\begin{abstract}
This paper illustrates how interactive whiteboards (IWBs) have been used to support the dynamic creation, capture and sharing of knowledge in primary and secondary schools in South Africa. It reports on the findings of a feasibility study undertaken by the Eastern Cape Department of Education to determine the perceived benefits and drawbacks of teachers and learners of using IWBs in the classroom. The research highlights how both teachers and learners can critically engage with multiple sources of information to construct their own knowledge, aiding learners in the learning process and helping teachers to scaffold that learning process. The study illustrates that IWBs have the potential to be beneficial in the South Africa classroom by affording teachers and learners a new medium through which they can create, capture and share knowledge.
\end{abstract}

\section{Introduction}

Don Tapscott [1], notes that today's generation of children have a fundamental preference for interactive media (the Internet, video games) rather than broadcast media (television, radio). Tapscott explains this preference, citing the hierarchical nature of broadcast media as compared to the shared power of interactive media. Applying this viewpoint of interactivity to an educational context, he calls for a shift in pedagogy from traditional "broadcast learning" (for example chalk-and-talk) to more interactive learning styles.

Aware of some of the on-going debates about the potential value of IWBs in schools and their potential value in realizing interactive learning styles, the Eastern Cape Department of Education (ECDoE) requested a team of researchers in the Computer Science and Education Departments at Rhodes University undertake one of a number of feasibility studies to investigate teachers' and learners' perceptions of the potential benefits and drawbacks of using IWBs - specifically the eBeam technology [2], a cheaper IWB technology that makes use of a radio transmitter attached to an ordinary non-interactive whiteboard - in schools in order to encourage evidence-based policy [3] and evidence-based practice [4].

This paper reports on the findings of a feasibility study undertaken in the Eastern Cape from August to December 2006, to determine the perceived benefits and drawbacks of teachers and learners of using IWBs in the classroom. In particular, it illustrates how IWBs 
have been used to support the dynamic creation, capture and sharing of knowledge in primary and secondary schools in South Africa.

\section{Related Work}

Before we can describe how learners create, capture and share knowledge using IWBs, we must first define what we understand knowledge to mean. Throughout this paper, we draw from Davenport and Prusak's definition of knowledge as "a fluid mix of framed experience, contextual information, values and expert insight that provides a framework for evaluating and incorporating new experiences and information" [5: 5]. Note that this definition has two components: firstly there is information that has been processed and internalized; and secondly, the purpose of knowledge is to evaluate new experiences. With this definition, we can now examine existing work in the field.

Previous research into interactive whiteboard use in the classroom elicited a number of positive and negative sentiments from learners. However, on the whole, learners seemed to enjoy the use of IWBs in the classroom $[6,7,8]$ and found them easy to use [6]. Learners also commented that they enjoyed the multimedia content that could be presented using the IWB, finding these lessons more interesting than traditional content [9]. Learners commented that the visual aspect of the IWB together with the verbal comments from their teachers complimented each other and helped them to better understand the content taught to them $[6,10]$. Learners felt that the IWB helped the teacher to explain concepts more effectively which allowed them to better understand and learn the new concepts $[10,11]$.

Linked to the visual aspect of the IWB, learners also discussed how the ability for the teacher to go back and forth over lesson content, easily repeating sections that learners might have struggled with also helped them to understand new concepts better and made for effective learning [9].

There is ongoing debate as to the reason behind the popularity of multimedia content on IWBs [12]. From a purely technical viewpoint, some refer to the IWBs ability to present information in vibrant colours, and the ability to move, manipulate, and zoom in on information as enhancing the learning process $[13,14]$. Others link its popularity with its ability to display a wide variety of information so concepts become more tangible and therefore easier to grasp [8]. Finally it is also argued that an IWB supports a wider range of learning styles, since teachers are able to draw on a variety of different resources to suit the learners' needs [9]. It is interesting to note the different theories underpinning the popularity of multimedia content for IWBs. We see most of these as a conflation of the attributes of a laptop-projector combination to an IWB, as the ability to display, manipulate (zoom, navigate), and adapt to different learning styles are all characteristics of a display rather than an interaction device (i.e. touch sensitive surface).

According to [15] the impact of using IWBs is seen in the interactivity of teaching and the associated participation of the learners. IWBs afford teachers the ability to either prepare content or materials in advance or during the lesson in front of the class. In addition, teachers are also able to quickly retrieve materials during lessons as needed for display to the whole class and are able to manipulate items directly on the display as one would with a standard computer interface [15]. This ability to create, capture and share knowledge using IWBs in the classroom was one of a number of affordances that were investigated during the course of this study. 


\section{User Study}

The main research question that the team sought to address was how and why do IWBs using "intelligent" or "smart" pens enable or constrain teaching and learning in South African primary and secondary schools. This paper analyses the results of this study, illustrating how IWBs are used to support the dynamic creation, capture and sharing of knowledge in South African primary and secondary schools.

In order to undertake the investigation, the ECDoE supplied eBeam projection systems, for two secondary schools and one primary school in Grahamstown. As the ECDoE was contemplating purchasing only one eBeam per school, we needed to explore not only how teachers could use IWBs in their individual classrooms, but what logistical issues might enable or constrain the optimal use of eBeam technology across at least three classrooms. One teacher, Teacher A, participated from the primary school and one teacher, Teacher B, participated from one of the secondary schools. In the other secondary school, three teachers, Teachers $\mathrm{C}, \mathrm{D}$, and $\mathrm{E}$, were involved in order to enable an investigation into the advantages and disadvantages of the mobility of the eBeam unit.

Teacher A is a Grade 5, 6 and 7 English first additional language teacher, who teaches a range of learners who mostly speak English as their second or third language. We observed her Grade 6 English first additional language class, with 29 learners. Teacher B, teaches English and Life Orientation. We observed his grade 11 English class, where the average age of the learners was 17 years old. This class had the largest class size out of all involved in the study. At its peak, there were 54 learners in the one small classroom. Teacher $\mathrm{C}$ is an Economics, Business Economics and Business Studies teacher. Throughout the duration of the study, we observed her grade 11 Business Economics class, with an average age of 17 years, and a total of 34 learners in the class. Teacher D is an English, History and Life Orientation teacher. During the course of the study we observed her Grade 9 English class, which consisted of 30 learners who were about 15 years old. The last teacher from School 3 is Teacher E, a mathematics and science teacher. We observed this teacher's grade 11 Mathematics class, where there were 22 learners enrolled in the class.

The three schools were chosen according to the key criteria that emerged from the literature and from other studies that were recently conducted in the same geographical area [16]. The Grahamstown area was chosen as it is close to Rhodes University where the research team is based, and because recent studies by the research team had enabled us to establish the necessary relationships with the school principals and teachers to be able to conduct a study of this nature. All schools involved in the study are equipped with ICT facilities, and are connected to the Internet. All teachers involved in the study have prior ICT experience (whether through formal or informal training) necessary to use ICTs in a classroom environment.

To ensure that teachers were provided with adequate training, four 2-hour training sessions were held. The first session was held at a local independent school that had recently purchased an IWB and a teacher, familiar with IWBs, demonstrated its use to the group of teachers, their school principals and the researchers. We assumed that it would be useful for teachers to observe how IWBs are used in a classroom situation. In subsequent training sessions, teachers: learned how to assemble, calibrate, and disassemble equipment; were given basic instructions on presenting lessons with the hardware; and presented a lesson they had prepared in front of the other participants and researchers; respectively. Throughout the training, researchers observed teachers' ICT skills and attempted to provide additional support to those who were less familiar with ICTs. Prior to the first, and on completion of the last observation, each teacher was interviewed to elicit their opinion on 
their experiences with the IWB. As we were also interested in the learners' perceptions, 10 learners from each of the teacher's classes were selected to participate in post-observation focus group interviews. The learners were selected according to their availability and willingness to participate in the focus group [17]. We chose the focus group approach to encourage discussion amongst the learners as some of them may have felt too shy to comment on a one-to-one basis.

\section{Findings and Discussion}

The findings in this section will discuss the two aspects of creating and capturing knowledge, and sharing knowledge separately.

\subsection{Create and Capture Knowledge}

This section describes the creation and capture of knowledge on the part of the learners and teachers separately, presenting comments from both teachers and learner experiences during the user study.

\subsubsection{Learners}

When describing the use of ICTs in class, Teacher B explained how in outcomes based education learners are encouraged to be the producers of knowledge and to understand how knowledge is constructed from various information sources. He commented, saying "And it actually works really well because they [the learners] are so much more in charge of getting the information and that's an important part of outcomes based curriculum that they must find the information. That they become aware of the producers of information and knowledge and they become aware of the how information is used and how they can use it and shape what they want to say".

Teacher B also discussed how the use of the IWB in the classroom allowed him to retrieve content and materials quickly and with ease, a benefit also discussed in [15]. He commented saying "They [the learners] benefited from the fact that firstly whatever resources we were using was much easier to get a hold of and to get into and then secondly there was a lot less hassle with having to write answers and clean the board and that whole repetitive schlep thing".

Teacher A's learners commented that the IWB supported creation and capture of knowledge as they could learn collaboratively: "It was much easier for us because we could see everything together, we didn't have to wait until our group got a chance to go and see the information on the computer". Extending this, Teacher B's learners commented that when using an IWB, their teacher could "pay more attention to us than writing on the board". Therefore IWBs in the classroom afforded learners the opportunity to be creators of knowledge, to have easy access to different sources of information and work collaboratively with each other and their teacher to produce and capture knowledge.

\subsubsection{Teachers}

Teacher B discussed in great detail how the use of the IWB allowed him to have easy access to different content and materials during his lessons. This meant that he was easily able to pull in extra material that he had not necessarily intended to use to support the learners understanding of concepts. This allowed him to respond to the changing dynamics of the 
learners and support their understanding of concepts as he taught them. This was a benefit also highlighted by researchers in [15]. He commented as follows:

Beforehand if I were to just use the laptop and projector I would have to pretty much make sure that I know where everything is stored and that you would have to set up beforehand on the hard-drive, you know, where everything is, but it is so much easier to navigate around the laptop or the hard-drive and find data sources and things like that. So you don't always have to have all the definitions already sorted out or already put on a slide or whatever and then that becomes part of the lesson, looking things up [...] Not only navigating around what data you have to teach but then also finding alternative sources and just basically being able to have all the sources at hand and being able to manipulate the data much more easily than having to come to the laptop and look for things, you can just do it right there.

From these comments we can clearly see that the IWB afforded Teacher B the opportunity to dynamically create and capture new knowledge in order to scaffold learning in his classroom. Teacher A made use of the IWB during her teaching to capture the knowledge of her learners. The IWB affords the teacher the ability to capture the pen strokes that the learners write on the IWB. This meant that when learners presented their collective group knowledge to the rest of the class by writing their brainstormed ideas on the IWB, Teacher A was able to capture the content, which was saved for later use by the learners and herself.

\subsection{Sharing Knowledge}

Throughout the teaching and learning environments involved in this study, we observed the process of sharing knowledge as consisting of three types of communication, which together resulted in the generation of a larger body of knowledge. In the first type of communication, teachers shared knowledge to the learners in the form of the prepared course material. Secondly, the learners may be involved in a collaborative discussion amongst themselves, sharing knowledge between learners and collectively creating knowledge. The third type of communication shared knowledge from the learners to the teacher. This section will illustrate these three types of communication separately, with reference to our observations from the user study.

\subsubsection{Teacher to Learner}

The ability to incorporate multimedia content into the teaching environment using the eBeam was a benefit that was highlighted by both learners and teachers during the course of this study. Throughout the study, teachers integrated numerous multimedia sources in their teaching, including: static images; Microsoft Encarta; Online sources such as governmental websites; Flash-based story books; PowerPoint Presentations; Microsoft Excel; and Geometer's Sketchpad. These findings are similar to those suggested by Hall and Higgins [7], who found this to be one of the major advantages of IWBs in learning environments cited by primary school students. Wall, Higgins and Smith quote a student saying "the pictures help you to understand what the teacher is talking about" [7: 860]. An example of this was when Teacher A used the IWB to display an image of the Southern Cross constellation to the learners: 'I remember when one of the other researchers from America was telling the children about the Southern Cross and they'd never heard of this. So I could go to the computer and show them - all forty students were around me, so I just set up the eBeam and everyone could see it on the large screen', aiding the learners in understanding what the American researcher was talking about. 
In addition, we found that learners often referred to the fun and thought-provoking content when using the eBeam in the classroom. The primary school learners in Teacher A's class, and Teacher A herself commented on the effectiveness of using Flash-based story books in class.

Four of the five focus groups commented that it was the ability to see or visualize what the teacher was talking about that helped them learn and understand new concepts; sharing knowledge from the teacher to the learner. The mathematics learners from School 3 were the most vocal about how this visualization helped them: "It's that we could see the things. You see, in a function in algebra you have the standard formula which is $a x^{2}+b x+c$... So we could actually see what effect ' $a$ ' had on the graph and what effect ' $b$ ' has on the graph immediately. [...] You can imagine that when you sketch a single graph by hand it takes a long time and then if you want to change the value of ' $a$ ' you have to draw again to see the differences. So we could learn more things in a single period than what we would learn over like a week". The mathematics teacher at School 3 also commented on advantages of the visual nature of the IWB saying that it makes it easier for the learners to learn and for him to teach them complicated abstract concepts in mathematics: '... because they can visualize them and see the effect that it has on changing the parameters. Shifting axes, moving sideway It becomes very interesting. But when you teach without anything that would make them see, it becomes very difficult.' These findings are similar to previous research work where it was reported that the visual aspects of the IWB helped learners to understand content, making the teacher's explanations more effective $[6,7,9,10,11]$. Learners "most commonly associated the IWB with visual ways of learning. The majority commented on how the visual and verbal elements complemented each other and promoted effective learning..." [18: 860] and consequently knowledge sharing.

\subsubsection{Learner to Learner}

During the course of this study the researchers noticed how the learners were able to make use of the IWB and other related ICT resources to help construct their knowledge within particular topics. The IWB and other related resources formed part of the collection of resources that learners employed to research about topics under discussion in the classroom. Learners were observed sharing knowledge amongst one another in two different contexts: when working in groups; and when reporting their findings to classmates from the front of the classroom (using the eBeam).

Working in groups, learners would discuss and compare their various sources, constructing their own knowledge with the materials available to them. Teacher E described how his learners worked collaboratively during his class, saying 'I ask groups to do different work. And then the groups come together and they share what they have learnt. They share that knowledge together'. Group work has often been acknowledged in related work as an associated benefit of the use of IWBs in teaching and learning environments. Levy [8] found that as IWBs allowed the teacher to present work more efficiently, more time was used for activity-based, interactive learning in groups. Pupils in this study found that sharing ideas with other classmates helped them to learn to explain and articulate their ideas.

As well as increased learner to learner participation in group contexts, Teacher $\mathrm{C}$ noted that her learners were more willing to participant when the IWB was used in class, saying '... [the learners] are more willing to advise the child who is writing [on the IWB] what next step to do. So the class is active'. These findings mirror those described by Levy [8], where she describes a shift in the roles of learners when using IWB, from a passive learning environment to more active participation where learners ask and answer questions that can be explored immediately on the IWB. 


\subsubsection{Learner to Teacher}

One of the major advantages claimed in existing work of using IWBs in classes is that learners appear to be more motivated to participate in their lessons when using an IWB. A study by BECTA suggest this motivation is due to "the high level of interaction - students enjoy interacting physically with the board, manipulating text and images" [19: 3]. During the course of this study the researches noticed that there was a definite enthusiasm amongst the learners when teachers were using the IWB in the classroom. During one of the classroom observations Teacher A commented to the researchers that learners in her class, particularly the weaker learners, were participating more eagerly than they had previously. When teachers asked questions in class there was generally a flurry of hands of learners wanting to answer, while excitement appeared even more pronounced when learners were presented with an opportunity to interact with the IWB directly.

As described in the previous section, across most classes that we observed, learners were encouraged to work together in groups. During these classes, teachers would then allow for time during which each of the groups would present their knowledge and understanding of the topic to the rest of the class. During this period the other learners and the teachers would discuss the topic in detail clarifying, correcting and confirming the knowledge constructed by each group. When not working in groups the learners were also encouraged to come and present some of their ideas and understandings on the IWB to the rest of the class which could then be discussed in detail by all the learners and their teacher. Teacher A described this enthusiasm to learn and participate that she had noticed in her weaker students, saying "But what I found is ... those learners are very much involved. ... I think its something new for everyone, and they felt that they could be part of the process too you know... I could see that they were trying to read along with the story. And afterwards when I tested them to see if they could read a line at least, I could see that they had improved".

Teacher D also described how learners seemed more willing to participate and contribute to the learning process when the teacher was teaching using an IWB, saying "The moment they see something new, they are more interested in using it. The moment you say the class will be held in the principal's classroom, they know we are going to be using the eBeam so they'll all rush in. And even if someone doesn't know the answer they always want to write on the board".

\section{Conclusion}

This paper has described how IWBs have been used in South African primary and secondary schools in the Eastern Cape Province to support the creation, capture and sharing of knowledge between teachers and learners. It has highlighted how both teachers and learners are afforded the opportunity to be creators and of knowledge through access to multiple digital resources. This process highlights how both teachers and learners can critically engage with multiple sources of information to construct their own knowledge, aiding learners in the learning process and helping teachers to scaffold that learning process. In addition, the visual nature of the IWB allowed teachers "to show" or learners "to see" or visualize the new content and concepts that they were learning about. The IWB also allowed both the teachers and the learners to capture the new knowledge that they were creating through various methods, such as saving brainstorming content from the learners as vector diagrams.

Finally, the IWB also afforded the teachers and learners the opportunity to share knowledge through group work and collaboration. This process corrected and solidified the 
knowledge that each participant was constructing. From this study it would appear that IWBs have the potential to be beneficial in the South Africa classroom by affording teachers and learners a new medium through which they can create, capture and share knowledge.

\section{References}

1. Tapscott, D. (2000) Growing Up Digital: The Rise of the Net Generation. New York, USA: McGraw-Hill.

2. Luidia Systems (2007) eBeam Interactive Whiteboard Technology. [cited 21 May 2007]; Available from: http://www.e-beam.com.

3. Pawson, R. (2004) Evidence-based policy: A realist perspective, in Making realism work: Realist social theory and empirical research., Carter, B. and New, C., Editors. Routledge: London.

4. Cordingley, P. (2004) Teachers using evidence: using what we know about teaching and learning to reconceptualize evidence-based practice, in Evidence-based practice in education, Thomas, G. and Pring, R., Editors. Open University Press: Maidenhead, Berkshire.

5. Davenport, T. and Prusak, L. (1998) Working Knowledge. Boston, USA: Harvard Business School Press.

6. Goodison, T. (2003) Integrating ICT in the classroom: a case study of two contrasting lessons. British Journal of Education Technology. 34: p. 549-567.

7. Hall, I. and Higgins, S. (2005) Primary school students' perception of interactive whiteboards. Journal of Computer Assisted Learning. 21(2): p. 102-117.

8. Levy, P. (2002) Interactive Whiteboards in learning and teaching in two Sheffield schools: a developmental study. Report by Department of Information Studies, University of Sheffield. Last accessed 21 May 2007. (Online http://dis.shef.ac.uk/eirg/projects/wboards.htm

9. Glover, D. and Miller, D. (2001) Running with technology: the pedagogic impact of the large scale introduction of interactive whiteboards in one secondary school. Technology, Pedagogy and Education. 10(3): p. 257-278.

10.Wall, K., Higgins, S., and Smith, H.J. (2005) "The visual helps me understand the complicated things": pupil views of teaching and learning with interactive whiteboards. British Journal of Education Technology. 36(5): p. 851-867.

11.McCallum, B., Hargreaves, E., and Gipps, C. (2000) Learning: the pupil's voice. Cambridge Journal of Education. 30(2): p. 275-289.

12.Smith, H.J., Higgins, S., Wall, K., and Miller, J. (2005) Interactive whiteboards: boon or bandwagon? A critical review of the literature. Journal of Computer Assisted Learning. 21: p. 91101.

13.Damcott, D., Landato, J., Marsh, C., and Rainey, W. (2002) Report on the use of the smart board interactive whiteboard in physical science. Report by Smarter Kids Foundation. Last accessed 21 May 2007. (Online http://smarterkids.org/research/paper3.asp

14.Edwards, J., Hartnell, M., and Martin, R. (2002) Interactive whiteboards: some lessons from the classroom. Micro Math. 18: p. 30-33.

15.Kennewell, S., Tanner, H., Jones, S., and Beauchamp, G. (2007) Analysing the use of interactive technology to implement interactive teaching. Journal of Computer Assisted Learning.

16. Brandt, I. (2006) Models of Internet connectivity for secondary schools in the Grahamstown Circuit, in Computer Science Department. Rhodes Univeristy: Grahamstown, South Afirca

17.Cohen, L., Manion, L., and Morrison, K. (2000) Research methods in education. London: Routledge.

18.Morgan, C. and Morris, G. (1998) Good teaching and learning : pupils and teachers speak. Philadelphia, USA: Open University Press.

19.Becta (2004) What the research says about interactive whiteboards. Report by BECTA. Last accessed 25 March 2008. (Online Report BEC1-15006) http://publications.teachernet.gov.uk/ eOrderingDownload/15006MIG2793.pdf 